\title{
The Logic of Uncertainty with Irrational Agents
}

\author{
Germano Resconi ${ }^{1}$ and Boris Kovalerchuk ${ }^{2}$ \\ ${ }^{1}$ Dept. of Mathematics and Physics, Catholic University Brescia, I-25121, Italy, resconi@numerica.it. \\ ${ }^{2}$ Dept. of Computer Science, Central Washington University, Ellensburg, WA 98922, USA, borisk@cwu.edu.
}

\begin{abstract}
Modern axiomatic uncertainty theories (fuzzy logic, probability theory and others) provide a calculus for manipulating with probabilities, membership functions, and degrees of belief when the initial values such as probabilities of elementary events are already given. These theories do not include a mechanism for getting initial uncertainty values. The value of these theories is in computing uncertainties of complex events that follow a structure imposed by axioms of a specific uncertainty theory. The lack of internal mechanism for getting initial values often means in the end that the same mechanism is applied for getting initial probability values, fuzzy logic membership functions, and belief functions. This is a source of much confusion -- what is the real difference between all of these theories. A resolution of this confusion is critical from both theoretical and practical viewpoints. We argue that adding an internal mechanism of getting uncertainty values means adding irrational, conflicting and interacting agents along with their contexts.
\end{abstract}

Keywords: uncertainty theory, fuzzy logic, interacting agents, irrationality, modal logic, possible worlds.

\section{Introduction}

The freedom of individual agents and their groups is a source of irrationality, inconsistency, and semantic uncertainty that the fuzzy set theory, the evidence theory, the rough set and others intend to model. The agents have a freedom to select a context. A set of agents is not a set of ordinary sets, because of their self-evaluation abilities. An agent can tell: "I am a reasonable agent". Can we separate the agent as a source of the statement from the statement itself? When the statement is written then it is an independent entity and we make a link between the statement and the agent by saying that agent $\mathrm{A}$ made statement $\mathrm{S}$. Modeling of self-evaluating sets has been a challenge in logic with several logic paradoxes discovered. Contexts often are personal for each agent and cannot be separated from the agents. In this paper we introduce a logic uncertainty theory in the context of evaluation of preferences of agents that includes a mechanism for getting initial uncertainty values as a part of the the- ory. This paper presents a further development of our previous works [Resconi, Jain, 2004; Kovalerchuk, 1990] that contain extensive references to related work. The fundamental analysis of relevant issues can be found in [Carnap Jeffrey, 1971; Halpern, 2005].

The paper is organized as follows: section 2 introduces agent logic evaluation in the preference system. Section 3 links it with fuzzy logic uncertainty and section 4 is devoted to links between agents modeled as worlds dealing with uncertainty. In this paper we show advantages of interpretation of fuzzy logic as an extension of the classical logic and probability theory with a mixture of rational and irrational agents. In this interpretation heuristic min max and others fuzzy logic operations can be naturally obtained and interpreted.

At first we provide a short review of the current situation in fuzzy logic that is depicted in table 1.

TABLE I.

\begin{tabular}{l|l}
\hline $\begin{array}{l}\text { 1. What } \\
\text { do users } \\
\text { want? }\end{array}$ & $\begin{array}{l}\text { A simple universal way to get }(1) \text { un- } \\
\text { certainty values } \mathrm{m}\left(\mathrm{a}_{\mathrm{i}}\right), \mathrm{m}\left(\mathrm{a}_{\mathrm{j}}\right) \text { of entities } \\
\mathrm{a}_{\mathrm{i}} \text { and } \mathrm{a}_{\mathrm{j}} \text { and }(2) \text { combinations } \mathrm{m}\left(\mathrm{a}_{\mathrm{i}} \& \mathrm{a}_{\mathrm{j}}\right) \\
\text { and } \mathrm{m}\left(\mathrm{a}_{\mathrm{i}} \mathrm{v} \mathrm{a}_{\mathrm{j}}\right) \text { from } \mathrm{m}\left(\mathrm{a}_{\mathrm{i}}\right) \text { and } \mathrm{m}\left(\mathrm{a}_{\mathrm{j}}\right) .\end{array}$ \\
\hline $\begin{array}{l}\text { 2. What } \\
\text { is in } \\
\text { reality? }\end{array}$ & $\begin{array}{l}\text { Complex dependency between } \mathrm{a}_{\mathrm{i}} \text { and } \mathrm{a}_{\mathrm{j}} \\
\text { and their contexts (including contra- } \\
\text { diction, irrationality and instability) }\end{array}$ \\
\hline $\begin{array}{l}\text { 3. What } \\
\text { is }\end{array}$ & $\begin{array}{l}\text { A collection of simple heuristic opera- } \\
\text { offered } \\
\text { to users? } \\
\mathrm{m}\left(\mathrm{a}_{\mathrm{i}} \& \mathrm{a}_{\mathrm{j}}\right)=\min \left(\mathrm{w}_{\mathrm{i}} \cdot \mathrm{m}\left(\mathrm{a}_{\mathrm{i}}\right), \mathrm{w}_{\mathrm{j}} \cdot \mathrm{m}\left(\mathrm{a}_{\mathrm{j}}\right)\right), \\
\mathrm{m}\left(\mathrm{a}_{\mathrm{i}} \& \mathrm{a}_{\mathrm{j}}\right)=\mathrm{w}_{\mathrm{i}} \cdot \mathrm{m}\left(\mathrm{a}_{\mathrm{i}}\right) \cdot \mathrm{w}_{\mathrm{j}} \cdot \mathrm{m}\left(\mathrm{a}_{\mathrm{j}}\right) \text { and other } \\
\mathrm{t}-\mathrm{norms} ; \\
\mathrm{m}\left(\mathrm{a}_{\mathrm{i}} \vee \mathrm{a}_{\mathrm{j}}\right)=\max \left(\mathrm{w}_{\mathrm{i}} \cdot \mathrm{m}\left(\mathrm{a}_{\mathrm{i}}\right), \mathrm{w}_{\mathrm{j}} \cdot \mathrm{m}\left(\mathrm{a}_{\mathrm{j}}\right)\right), \\
\mathrm{m}\left(\mathrm{a}_{\mathrm{i}} \mathrm{va} \mathrm{a}_{\mathrm{j}}\right)=\mathrm{w}_{\mathrm{i}} \cdot \mathrm{m}\left(\mathrm{a}_{\mathrm{i}}\right)+\mathrm{w}_{\mathrm{j}} \cdot \mathrm{m}\left(\mathrm{a}_{\mathrm{j}}\right) \text { and other } \\
\mathrm{t}-\text { conorms. }\end{array}$ \\
\hline
\end{tabular}

The conclusion from this table is that now users have simple (not universal) operations without tools to capture complex dependencies. Obviously, this should be compensated. Engineers as users adjust weights $\mathrm{w}_{\mathrm{i}}, \mathrm{w}_{\mathrm{j}}$ and t-norm or t-conorm. What was used to do this? It is intuition or available data. In the case of intuition, the final success should be attributed to users' engineering art rather than the tools and theory used. In the case when data are available we have now a productive neuro-fuzzy interpolation approach in fuzzy control. However, we should 
rather attribute the success to the fact data are available than to set of predefined fizzy logic operations. We need a theory that will go beyond current empirical way of adjusting coefficients $\mathrm{w}_{\mathrm{i}}$ and operations by users.

This problem is not new [e.g., Elkan, 1993] and is very difficult. How to build an uncertainty theory that will be simple for use, universal enough and capture complex dependencies in the real world? We claim that there is no shortcuts that will allow do this. In reality this naïve desire of having a shortcut means passing the complexity of the real problem to the user

We claim that that a sound solution is in more complex context-dependent operations, that is $\mathrm{m}(\mathrm{a} \& \mathrm{~b})$ can not be a function of only $m(a), m(b), f(m(a), m(b)$ if want to deal with complexity of the real problems inside of the theory not outside of it.

The fundamental strength of the probability theory is that it does not look for shortcuts. However it does not provide a mechanism for getting initial uncertainty values inside of the theory. Our goal is to develop a logic of uncertainty that will do this inside of the theory. To do this we use concepts of irrational agents, modal logic, and contexts. We start from an example below to set up a realistic situation for further discussion.

\section{Framework of Irrational Agents}

Let us consider 100 agents $G_{i}$, two cars A and B and preference relation " $>$ " between cars to be assigned by each of these agents (potential buyers). We define a Boolean variable $X$ such that $X=1$ (True) if $A>B$ else $\mathrm{X}=0$ (False). Each agent $\mathrm{G}_{\mathrm{i}}$ answered a questionnaire with two options offered: (1) $A>B$ is true and (2) $A>B$ is false. Say 70 agents out of 100 marked $A>B$ is true giving a fuzzy logic membership function value $\mathrm{m}(\mathrm{A}$ $>$ B) $=70 / 100$.

This is a classical relative frequency used in the probability theory, which normally implies the necessity of using probability theory operations that differ from fuzzy logic operations for computing uncertainty values of complex events. Thus, the question is: "Can fuzzy logic operations be justified in such situations?" We state that there is a way to do this. Implicitly we assumed that any agent that marks in the questionnaire "A > B is true" does not mark an opposite preference " $\mathrm{B}>\mathrm{A}$ is true". This is a fundamental assumption of the probability theory - elementary events are disjoint and mutually exclusive and one of them needs to happen. (They must answer something and even nonmarking an option means something)

If an agent marks both options, his/her answers will be discarded, as non-valid and only agents with a single answer will be counted in relative frequencies. This is needed to keep fundamental additivity princi- ple (assumption) of the probability theory at work and consequently to be able to use the probability theory operations.

Now the question is: "How often is this mutual exclusion assumption violated in modeling real world we processes?" Let us have 100 agents, 69 agents prefer A to B and only one agent out of 100 agents is irrational who marked both options. In this case for many practical tasks $\mathrm{m}(\mathrm{A}>\mathrm{B})=69 / 100$ does not differ significantly from $70 / 100$ or $68 / 100$ if his/her answers would be rational However, if 50 agents behave irrationally (use both alternatives) and if we discard their responses then we may get $\mathrm{m}(\mathrm{A}>\mathrm{B})=(70-50) /(100$ $50)=0.4$, which differs significantly from 0.7 . The number of irrational agents is not known in advance and it makes sense to have a theory that will be able to deal with a mixture rational and irrational agents. In the case of customer preferences irrational behavior is quite common.

One of the ways to deal with such mixed situation is to modify a questionnaire (probability space) to make three alternatives: (1) " $\mathrm{A}>\mathrm{B}$ is true", (2) " $\mathrm{A}>\mathrm{B}$ is false", and (3) both " $A>B$ is true and $A>B$ is false". We will denote these alternatives $W_{1}=\{T, F, T \& F\}$ that is an extension of a set of rational alternatives used the probability theory $\mathrm{W}_{0}=\{\mathrm{T}, \mathrm{F}\}$. The last contradictory alternative $\mathrm{T} \& \mathrm{~F}$ is specifically designed for irrational agents. If we assume that alternatives in $\mathrm{W}_{1}$ are mutually exclusive (each time the agent selects only one of them) then the probability theory can be applied. Thus, at first glance, we fixed a problem with a simple adjustment. However, implicitly we made an assumption that agents have a limited irrationality (we will call it level 1 of irrationality, $L_{l}$ ), that is having three alternatives T, F, T\&F about preference statement, $\mathrm{A}>\mathrm{B}$, the agent will not violate mutual exclusion further. The agent will mark only one alternative out of these three alternatives and will not mark two or three of them simultaneously.

Now assume that we have all agents at the level $L_{l}$ with alternatives from $\mathrm{W}_{1}$ such that $\mathrm{m}(\mathbf{a})=0.7$ for $\mathbf{a} \equiv$ $\mathrm{A}>\mathrm{B}=$ true and $\mathrm{m}(\mathbf{b})=0.3$ for $\mathbf{b}=(\mathrm{A}>\mathrm{B}=$ true $) \quad \&$ $(A>B=$ false $)$. What is the value of $m(\mathbf{a} \& \mathbf{b})$ ? We have $\mathbf{b}$ nested in $\mathbf{a}, \mathbf{a} \supset \mathbf{b}$, thus $\mathrm{m}(\mathbf{a} \& \mathbf{b})=\mathrm{m}(\mathbf{b})=0.3$. In general terms for nested expressions we have $\mathrm{m}(\mathbf{a} \& \mathbf{b})=\min (\mathrm{m}(\mathbf{a}), \mathrm{m}(\mathbf{b}))$, that is a well known fuzzy logic operation. Similarly we can justify max operation of disjunction, $\mathrm{m}(\mathbf{a} \vee \mathbf{b})=\max (\mathrm{m}(\mathbf{a}), \mathrm{m}(\mathbf{b}))$, that is 0.7 in our example.

If the agent wishes to mark, both $\mathrm{T}$ and $\mathrm{T} \& \mathrm{~F}$ then this agent is more irrational than level $\mathrm{L}_{1}$ allows. We will call such agent as an irrational agent at level $\mathbf{2}, \mathrm{L}_{2}$. To accommodate $\mathrm{L}_{2}$ agents in the probability theory framework we need to expand the set of alternatives again and have $\mathrm{W}_{2}=\{\mathrm{T}, \mathrm{F}, \mathrm{T} \& \mathrm{~F}, \mathrm{~T} \&(\mathrm{~T} \& \mathrm{~F})\}$ built consequently from $\mathrm{W}_{1}=\{\mathrm{T}, \mathrm{F}, \mathrm{T} \& \mathrm{~F})$ and $\mathrm{W}_{0}=\{\mathrm{T}, \mathrm{F}\}$. Next we may get an agent at the level of irrationality $\mathrm{L}_{3}$ that 
mark two alternatives from $\mathrm{W}_{2}$. This will force us to expand $\mathrm{W}_{2}$ again to $\mathrm{W}_{3}=\{\mathrm{T}, \mathrm{F}, \mathrm{T} \& \mathrm{~F}, \mathrm{~T} \&(\mathrm{~T} \& \mathrm{~F})$, $\mathrm{T} \&(\mathrm{~T} \&(\mathrm{~T} \& \mathrm{~F}))\}$ Next the same consideration can lead us to agents at level of irrationality $\mathrm{L}_{4}$ and a set of alternatives $\mathrm{W}_{4}$. This process generating can continue indefinitely (regress to infinity) if we do not limit the level of agent's irrationality.

For highly irrational agents (large levels, $\mathrm{L}_{\mathrm{i}}$ ) the number of nested elements in $\mathrm{W}_{\mathrm{i}}$ is large too and grows when the level of irrationality $\mathrm{i}$ grows. Thus, for many AND/OR expressions min max operations can be valid for such $\mathrm{L}_{\mathrm{i}}$ and $\mathrm{W}_{\mathrm{i}}$, in contrast with the situation with rational agents working in $\mathrm{W}_{0}$.

This consideration shows the need in an uncertainty theory that will deal with such situation of mixture of rational and irrational agents as an extension of the probability theory. The additional challenge is that we may have agents with different and unknown levels of irrationality and we may not be able to limit agents' irrationality.

\section{Logic of uncertainty framework}

Below we outline a logic of uncertainty with contradictory agents to be able to give measures of uncertainty as an internal part of the theory.

The Logic of Uncertainty contains the following components that are explained below:

$<\{A\}, W, M,\{L w)$, Ont $_{w}, S(A), T(A, B), \operatorname{Com}(A, B)>$.

- $\{\mathrm{EA}\}$ is a set of agents that includes Evaluation Agents (EAs) that evaluate statements and Ontology Agents (OAs) that set up the structure and language.

- $\mathrm{W}=\{\mathrm{w}\}$ is a set of Possible Worlds,

- $\mathrm{M}:\{\mathrm{EA}\} \rightarrow \Gamma(\mathrm{W})$ and $\Gamma(\mathrm{W})$ is s set of all subsets of W.

- $\mathrm{L}_{\mathrm{w}}$ is a Language that is used to describe world $\mathrm{w}$.

- $\mathrm{Ont}_{\mathrm{w}}$ is an Ontology of the $\mathrm{w}$ expressed in $\mathrm{L}_{\mathrm{w}}$. It includes the level of agent's irrationality. The ontology agent sets up $\mathrm{M}$, Ont $\mathrm{w}_{\mathrm{w}}$, and $\mathrm{L}_{\mathrm{w}}$.

- $\mathrm{S}(\mathrm{A})$ is a Irrationality Statement, $\mathrm{S}(\mathrm{A})=1$ if the agent $\mathrm{A}$ is irrational and $\mathrm{S}(\mathrm{A})=0$ if the agent is rational.

- $\mathrm{T}(\mathrm{A}, \mathrm{B})$ is a Contradiction Relation, $\mathrm{S}(\mathrm{A}, \mathrm{B})=1$ if worlds of agents $A$ and $B$ contradict to each others.

- $\operatorname{Com}(\mathrm{A}, \mathrm{B})$ is a Communication Relation, $\operatorname{Com}(\mathrm{A}, \mathrm{B})=1$ if agents $\mathrm{A}$ and $\mathrm{B}$ communicate and A can change $\mathrm{m}(\mathrm{A}, \mathrm{V})$ because $\mathrm{A}$ knows $\mathrm{m}(\mathrm{B}, \mathrm{V})$, where $\mathrm{m}(\mathrm{A}, \mathrm{V})$ and $\mathrm{m}(\mathrm{B}, \mathrm{V})$ are truth values assigned by agents $\mathrm{A}$ and $\mathrm{B}$ to statement $\mathrm{V}$ in their worlds $\mathrm{w}_{\mathrm{A}}$ and $\mathrm{w}_{\mathrm{B}}$.

The accessibility relation in modal logic influenced introduction of this relation.
The agent $\mathrm{A}$ is an entity whose internal knowledge and belief is the set $\mathrm{W}_{\mathrm{A}}$ of worlds, (possible worlds) mapped to it by $\mathrm{M}: \mathrm{M}(\mathrm{A})=\mathrm{W}_{\mathrm{A}}$.

Each worlds $\mathrm{W}$ consist of statements in language $\mathrm{L}_{\mathrm{w}}$. (each world can be viewed as a model [Mal'cev, 1973], where the agent can assign only crisp values (true/false) to statements.

The contradiction between agents means that there exists a statement $\mathrm{V}$ in $\mathrm{w}_{\mathrm{A}}$ and $\mathrm{w}_{\mathrm{B}}$ such that $\mathrm{V}$ true in $\mathrm{W}_{\mathrm{A}}$ and false in $\mathrm{W}_{\mathrm{B}}$. Thus, each agent can view another agent as is irrational if they communicate.

In the next section we present a mechanism to compute uncertainty values of statements in the preference system in line with this framework.

\section{Logic of uncertainty in prefer- ence system}

For a given set of products the preferences of agents (evaluators, customers) are given as a preference graph [Ishizu, Gehrmann, 2002]. Product G1 is connected by an arrow to another product G2 when the agent prefers G1 to G2. If an agent cannot compare them then there is no arrow between G1 and G2. Say, Car A is a sports car, car B is a family car, and car C is a car for transporting goods. The agent $\mathrm{C} 1$ may have a transitive preference graph shown in Fig. 1 for the attribute "fuel efficiency". A coincidence matrix shown in TABLE 2 represents this graph, where 1 (true) indicates that the agent prefers product $\mathrm{X}$ to product $\mathrm{Y}$. The value 0 (false) means that agent prefers product $Y$ to product $\mathrm{X}$.

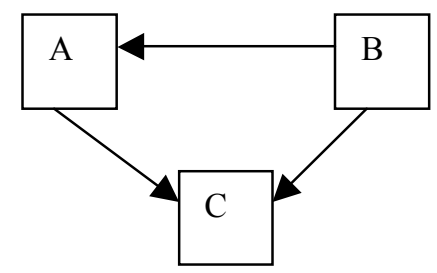

Fig. 1. Preference graph when the evaluator $\mathrm{C}_{1}$ uses the attribute "fuel efficiency".

TABLE 2

AGENT'S “FUEL EFFICIENCY” PREFERENCE TABLE

\begin{tabular}{|l|l|l|l|}
\hline & A & B & C \\
\hline A & 1 & 0 & 1 \\
\hline B & 1 & 1 & 1 \\
\hline C & 0 & 0 & 1 \\
\hline
\end{tabular}

The absence of the value in the table means the agent (1) did not evaluate preference yet, or (2) cannot evaluate the preference. In the first case for the rational agent the transitive closure of the preference relation can be obtained by reasoning (If $\mathrm{B}>\mathrm{A} \& \mathrm{~A}>\mathrm{C}$ then $\mathrm{B}>\mathrm{C}$ ), where " $>$ " denotes the preference relation. In the second case both preference relation $\mathrm{A}>\mathrm{C}$ and $\mathrm{C}>\mathrm{A}$ are false. 
Different evaluators may have different graphs. Now we can introduce a fuse operator

$\mu(X, Y)=\frac{C_{1}(X, Y)+C_{2}(X, Y)+\ldots . .+C_{N}(X, Y)}{N}$

where a pair of variables $(\mathrm{X}, \mathrm{Y})$ denotes two products $\mathrm{X}$ and $\mathrm{Y}$ connected by an arrow in the graph and $\mathrm{C}_{\mathrm{k}}(\mathrm{X}, \mathrm{Y})$ is the evaluation value $(0$ or 1$)$ for the agent $C_{k}$ when the agent compares the product $X$ with the product Y. For example, for car A and car B, and the attribute "car fuel efficiency" we may have

$$
\mu(A, B)=\frac{C_{1}(A, B)+C_{2}(A, B)+\ldots . .+C_{N}(A, B)}{N}=\frac{M}{N}
$$

where $\mathrm{M} \leq \mathrm{N}$ is the number of agents that prefer $\mathrm{A}$ to $\mathrm{B}$ and $\mathrm{N}$ is a total number of agents. Note that the fuse operator is not commutative. Now given two attributes $\mathrm{p}_{1}=$ "car fuel efficiency" and $\mathrm{p}_{2}=$ "car inner space" we can compose the $\mu(\mathrm{A}, \mathrm{B})_{\mathrm{p} 1 \wedge \mathrm{p} 2}$, for two cars $\mathrm{A}$ and $\mathrm{B}$ :

$$
\mu(A, B){ }_{p_{1} \wedge p_{2}}=\frac{1}{N} \sum_{i=1}^{N}\left(C_{i}(A . B)_{p_{1}} \wedge C_{i}(A, B) p_{2}\right)
$$

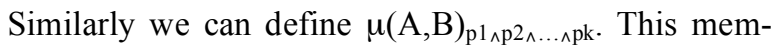
bership function indicates how consistent the preferences of all agents about cars $\mathrm{A}$ and $\mathrm{B}$ relative to attributes $\mathrm{p}_{1}, \mathrm{p}_{2}, \ldots, \mathrm{p}_{\mathrm{k}}$. It is assumed here that "and" operator is defined is a standard way, $1 \wedge 0=0,1 \wedge 1=1$, and $0 \wedge 0=0$.

When the preference graph is a non-transitive graph or a graph with cycles, we have an irrational agent (with irrational preferences). A preference graph for a rational agent should be transitive: if for the agent car $\mathrm{C}$ is better than $\mathrm{B}$ and $\mathrm{B}$ is better than $\mathrm{A}$ then $\mathrm{C}$ should be better then A. But in Fig. 1 there is an arrow for which $\mathrm{A}$ is better than $\mathrm{C}$. This generates a contradiction with respect to rational deduction that $\mathrm{C}$ is better than A. More formally, in a graph shown in Figure 2(b), we have $\mathrm{P}(\mathrm{C}, \mathrm{B})=1 \quad$ (true), $\mathrm{P}(\mathrm{B}, \mathrm{A})=1$ (true), but non of relations $\mathrm{P}(\mathrm{A}, \mathrm{C})$ and $\mathrm{P}(\mathrm{C}, \mathrm{A})$ is true, $\mathrm{P}(\mathrm{A}, \mathrm{C})=0$ (false) and $\mathrm{P}(\mathrm{C}, \mathrm{A})=0$ (false), because the agent refused to compare $\mathrm{A}$ and $\mathrm{C}$. Thus, $\neg \mathrm{P}(\mathrm{A}, \mathrm{C})=1$ and $\neg \mathrm{P}(\mathrm{C}, \mathrm{A})=1$. On the other hand $\mathrm{a}$ rational agent should assume transitivity of the preference relation. Thus this agent should be able to infer that $\mathrm{P}(\mathrm{C}, \mathrm{A})$ is true, $\mathrm{P}(\mathrm{C}, \mathrm{A})=1$ and respectively, $\neg \mathrm{P}(\mathrm{A}, \mathrm{C})=0$. Combining properties $\mathrm{P}(\mathrm{C}, \mathrm{A})=1$ and $\neg \mathrm{P}(\mathrm{C}, \mathrm{A})=1$ we get a logical contradiction that is true,

$$
\mathrm{P}(\mathrm{C}, \mathrm{A}) \wedge \neg \mathrm{P}(\mathrm{C}, \mathrm{A})=\text { True. }
$$

Similarly combining $\mathrm{P}(\mathrm{A}, \mathrm{C})=0$ and $\neg \mathrm{P}(\mathrm{A}, \mathrm{C})$ we get a false tautology

$$
\mathrm{P}(\mathrm{A}, \mathrm{C}) \vee \neg \mathrm{P}(\mathrm{A}, \mathrm{C})=\text { False }
$$

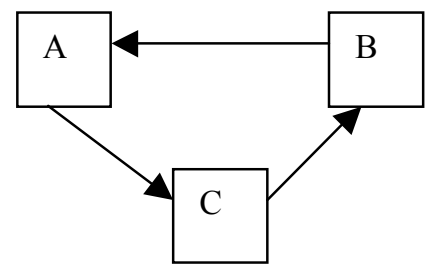

b

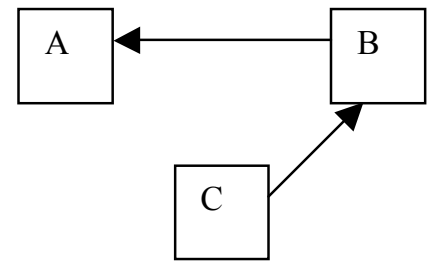

Fig 2. Cycle graph (a). Non-transitive evaluation graph (b)

Figure 2 (b) shows that there is no direct comparison between $\mathrm{A}$ and $\mathrm{C}$. How to explain this? One option is that the agent is irrational, i.e., in spite of normative transitivity the agent does not accept it. Another option is that the agent simply was not asked and if asked would agree with transitivity and change preferences accordingly.

To model irrational agents we propose a new logic uncertainty where contradiction can be true and tautology false for some statements of such irrational agents.

\section{Operations with uncertainties}

Let $E(X)=\left(X_{1}, X_{2}, \ldots, X_{p}\right)$ and $E(Y)=\left(Y_{1}, Y_{2}, \ldots, Y_{p}\right)$ be vectors of binary evaluations (true/false) of attributes $\mathrm{X}$ and $\mathrm{Y}$ by $\mathrm{p}$ agents. Given these $\mathrm{X}$ and $\mathrm{Y}$ we have the composition rule

$$
\begin{aligned}
& \left(X_{1}, ., X_{p}\right) \wedge\left(Y_{1}, . ., Y_{p}\right)=\left(Y_{1} \wedge X_{1}, \ldots, Y_{p} \wedge X_{p}\right) \\
& \left(X_{1}, \ldots, X_{p}\right) \vee\left(Y_{1}, \ldots, Y_{p}\right)=\left(Y_{1} \vee X_{1}, \ldots, Y_{p} \vee X_{p}\right) \\
& \neg\left(X_{1}, \ldots, X_{p}\right)=\left(\neg X_{1}, \ldots, \neg X_{p}\right)
\end{aligned}
$$

We define the $A N D$ fuse operator of evaluations $\mathrm{X}_{\mathrm{i}}$ of $\mathrm{p}$ agents of the attribute $\mathrm{X}$ and $\mathrm{Y}$ as

$$
\begin{aligned}
& \mu(X)=\frac{m_{1}\left(X_{1}\right)+\ldots+m_{p}\left(X_{p}\right)}{m_{1}+m_{2}+\ldots+m_{p}} \\
& \mu(Y)=\frac{m_{1}\left(Y_{1}\right)+\ldots+m_{p}\left(Y_{p}\right)}{m_{1}+m_{2}+\ldots+m_{p}} \\
& \mu(Y X)=\frac{m_{1}\left(Y_{1} X_{1}\right)+\ldots+m_{p}\left(Y_{p} X_{p}\right)}{m_{1}+m_{2}+\ldots .+m_{p}}
\end{aligned}
$$

where $\mu$ is the membership function, and $m_{1}, \ldots, m_{p}$ are the importance ( weights) of agents. When the agents are equal in importance we have the traditional fuse operator. The OR fuse operator is defined simi- 
larly by using $\mu(\mathrm{X} v \mathrm{Y})$ instead of $\mu(\mathrm{XY})$ in Eq.(7) with the definition of $X \vee Y$ fro vectors from Eq. (6).

The new negation introduces an irrational term $S_{k}$ that is responsible of the difference between the classical logic and logic of uncertainty. In fact we assume that

$$
\begin{aligned}
& (\bar{X})=\overline{\left(X_{1}, X_{2}, \ldots, X_{p}\right)}= \\
& \left.\left(\overline{X_{1}} \oplus S_{1}\right), \overline{X_{2}} \oplus S_{2}, \ldots ., \overline{X_{p}} \oplus S_{p}\right)
\end{aligned}
$$

where $\oplus$ is the XOR operation. In this case we have

The new negation is the extension of the negation operation in the classical logic and can be used to give models for negation in the fuzzy logic.

\section{Logic of uncertainty for interde- pendent worlds}

In the classical Kolmogorov's definition of the probability [Shafer, Vovk, 2001; Halpern, 2005] it is assumed that the worlds are independent and are not connected with others. The introduction of relations between worlds (agents) via a communication relation Com (accessible relation R) can change the Kolmogorov's axioms as follows:

1) $\mathrm{F}$ is a field of sets. This means that if $\mathrm{F}$ contains $\mathrm{E}$ and $G$ then $F$ contains their intersection, union, and difference.

2) F contains the set $\Omega$ (sample space $\Omega$ or universal set). Together with axiom 1 , this says that $F$ is an algebra of sets. When $\mathrm{F}$ is closed under countable infinite intersection and union it is called a $\sigma$ algebra.

3) Another set $\mathrm{W}=\left\{\mathrm{w}_{\mathrm{i}}\right\}$ is given. Each element of $\mathrm{W}$ is called a world. Every element $\mathrm{Ob}_{\mathrm{i}}$ of $\Omega$ is associated with one and only one world $\mathrm{w}_{\mathrm{i}}$ in $\mathrm{W}$ and with an accessible relation $\mathrm{R}$ in $\Omega$. If $\mathrm{R}\left(\mathrm{Ob}_{\mathrm{i}}, \mathrm{Ob}_{\mathrm{j}}\right)=\mathrm{T}$ then element $\mathrm{Ob}_{\mathrm{i}}$ can "access" element $\mathrm{Ob}_{\mathrm{j}}$, that is it can get information about element $\mathrm{Ob}_{j}$. Having each $\mathrm{Ob}_{\mathrm{i}}$ associated with some world $\mathrm{w}_{\mathrm{i}}$, it is possible to say that world $\mathrm{w}_{\mathrm{i}}$ can "access" world $\mathrm{w}_{\mathrm{j}}$, that is it can get information about world $\mathrm{w}_{\mathrm{j}}$. In the simplest case $\mathrm{Ob}_{\mathrm{i}}$ can be the same as $\mathrm{w}_{\mathrm{i}}$. Elements $\mathrm{Ob}_{\mathrm{i}}$ also sometimes called objects or elementary events. Similarly set $\mathrm{E}$ of elementary events $\mathrm{Ob}_{\mathrm{i}}$ is called a set of events. The predicate $\mathrm{Q}_{\mathrm{j}}\left(\mathrm{Ob}_{\mathrm{i}}\right)$ is defined for each elementary event $\mathrm{Ob}_{\mathrm{i}}$. If $\mathrm{Q}_{\mathrm{j}}\left(\mathrm{Ob}_{\mathrm{i}}\right)=$ True then we say that event $\mathrm{Ob}_{\mathrm{i}}$ is true (takes place). In essence, predicate $Q_{j}$ defines the concepts elementary events. The predicate $Q_{j}$ creates a structure of events. More generally, a set of predicates $\mathrm{Q}_{\mathrm{j}}$ and axioms that set up relations between these predicates provide a structure for the set of the worlds. An Ontology Agent (OA) can set up this structure and language $\mathrm{L}$ and evaluation agents (EAs) can evaluate if $\mathrm{Q}_{\mathrm{j}}\left(\mathrm{Ob}_{\mathrm{i}}\right)$ is true or not for a world $\mathrm{w}_{\mathrm{i}}$ that is associated with $\mathrm{Ob}_{\mathrm{i}}$.

4) A non-negative real number $\mathrm{P}(\mathrm{E})$ is assigned to each set $\mathrm{E}$ in $\mathrm{F}$. This number $\mathrm{P}(\mathrm{E})$ is called the probability of the event (set) E. Note: traditionally $\mathrm{P}(\mathrm{E})$ reflects the number of elementary events in E relative to total number of events in $\Omega$ [14].

5) $\mathrm{P}(\Omega)=1$. This axiom reflects the intuitive idea that number of elementary events in $\Omega$ relative to itself is 1 .

6) If $\mathrm{E}$ and $\mathrm{G}$ are disjoint $(\mathrm{E} \cap \mathrm{G}=\varnothing)$ then

$$
\mathrm{P}(\mathrm{E} \cup \mathrm{G})=\mathrm{P}(\mathrm{E})+\mathrm{P}(\mathrm{G}) \text {. }
$$

7) Two non-negative real numbers $P_{1}(E)$ and $P_{2}(E)$ are assigned to each set $E$ in $F$ such that $P_{1}(E) \leq$ $\mathrm{P}(\mathrm{E}) \leq \mathrm{P}_{2}(\mathrm{E})$, where $\mathrm{P}_{1}(\mathrm{E})$ is the relative number of worlds in $\mathrm{E}$ that are at least necessary true for one element in $E, \mathrm{P}_{2}(\mathrm{E})$ is the relative number of worlds that are at least possibly true for one element in $E$. Thus, $\mathrm{P}_{1}(\mathrm{E})$ and $\mathrm{P}_{2}(\mathrm{E})$ are lower and upper limits of probability $\mathrm{p}(\mathrm{E})$, also $\left[\mathrm{P}_{1}(\mathrm{E})\right.$, $\left.\mathrm{P}_{2}(\mathrm{E})\right]$ is an interval probability.

8) The measure $\mathrm{m}(\mathrm{E})$ is the relative number of worlds that are possible true for all the elements in $E$ and not possible true for other elements of $F$.

\section{Conclusion}

Fuzzy logic, probability theory, and other uncertainty theories compute uncertainties of complex events that follow a structure imposed by their axioms. These theories have no an internal mechanism for getting initial uncertainty values. We had shown how this mechanism can be built by incorporating irrational, conflicting and interacting agents and worlds. This approach can be applied to many tasks beyond the customer preference system we used for illustration.

\section{References}

[1] Carnap R., Jeffrey R, Studies in Inductive Logics and Probability, vol. 1, 35-165 Berkeley, CA, University of California Press, 1971.

[2] Elkan,C., The paradoxical success of fuzzy logic. In proceeding of the National Conference on Artificial Intelligence, pp. 698703, Washington D.C. August 1993

[3] Halpern, J. Reasoning about uncertainty, MIT, 2005

[4] Kovalerchuk B., Analysis of Ganes' logic of uncertainty, In Proceeding of NAFIPS '90 vol.2 edited by I.B. Turksen, Toronto Canada pp.293-295, 1990.

[5] Malcev A.I. Algebraic Systems, Springer, 1973.

[6] Resconi, G., Jain, L. Intelligent agents, Springer Verlag, 2004

[7] Ishizu S., Gehrmann, A., Attributes Structure of Complex Systems Evaluation, Proc of 2002 Conf. of Manufacturing Complexity Network, pp. 323-338, 2002.

[8] Shafer, G., Vovk, V. Probability and Finance It's Only a Game!, Wiley Series in Probability and Statistics, 2001 